\title{
Supporting Information for \\ Enhanced Surface Activity of MWW Zeolite Nanosheets Prepared via a One-Step Synthesis
}

Yunwen Zhou ${ }^{1}$, Yanyu Mu ${ }^{2}$, Ming-Feng Hsieh ${ }^{l}$, Bernd Kabius ${ }^{2}$, Carlos Pacheco ${ }^{3}$, Carol Bator ${ }^{4}$, Robert M Rioux ${ }^{2,3,{ }^{*}}$, and Jeffrey D. Rimer ${ }^{1, *}$

${ }^{1}$ Department of Chemical and Biomolecular Engineering, University of Houston, Houston, TX 77204, USA

${ }^{2}$ Department of Chemical Engineering, The Pennsylvania State University, State College, PA 16801, USA

${ }^{3}$ Department of Chemistry, The Pennsylvania State University, State College, PA 16801, USA

${ }^{4}$ Huck Institutes of Life Sciences, The Pennsylvania State University, State College, PA 16801, USA

*Correspondence sent to: rmr189@psu.edu and jrimer@central.uh.edu

\section{Table of Contents}

Experimental Methods.................................................................. 22

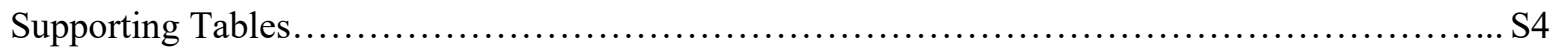

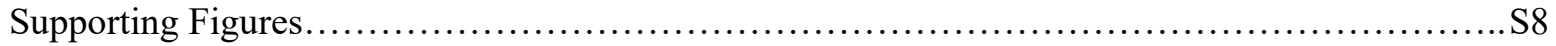

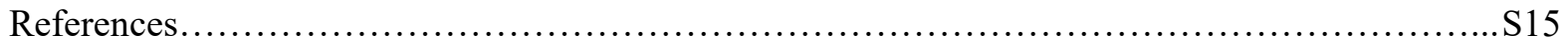




\section{Experimental Methods}

Cryo-TEM sample preparation. Zeolite dispersions $(\sim 3 \mathrm{mg} / \mathrm{mL})$ in water were drop-cast $(\sim 1.5 \mu \mathrm{L}$ volume $)$ onto Quantifoil grids (1.2/1.3/300 mesh $\mathrm{Cu}$ ) (Ted Pella) which were subjected to glow discharge (PELCO easiGlow $^{\text {TM }}$ Glow Discharge Cleaning System $)$ in air $(0.3$ mbar $)$ at $20 \mathrm{~mA}$ for $40 \mathrm{~s}$. For the grids, 1.2 refers to the hole sizes on the Quantifoil grid in $\mu \mathrm{m}$, while 1.3 refers to the average hole size in carbon support in $\mu \mathrm{m}$. The glow discharge ensured the TEM grids were hydrophilic. Prior to drop-casting, suspensions were sonicated in a water bath to ensure zeolite particles were fully suspended since they tended to settle out without agitation. After allowing the grids to dry by evaporation in the atmosphere, the Quantifoil grids were clipped into autoloader cartridges and loaded into the Krios autoloader at room temperature. Grids were cooled inside the Krios to liquid nitrogen temperature and maintained at cryogenic temperature throughout screening and data collection.

Procedure for analysis of $M W W$ sample thickness. In order to measure the thickness of nanosheets whose surface normal ((001) direction) are perpendicular the the electron beam, we processed images (which contained one of more of these edge-on oriented sheets) with Digital Microgrpah. A sufficient number of crystals in this orientation could be identified over numerous micrographs allowing for the collection of substantial statistics (150-500 individual measurements). We chose vertically oriented crystals over flatlying crystals since the latter had uniform thickness and minimum intensity at the boundaries enabling more accurate measurement of thickness. Thickness for each vertical crystal was determined from the distance between two positions of intensity minima in the line profile (Figure S2). Nanosheets were only included into the data pool if they are visualized edge-on. Measurements on sheets tilted away from this condition are subject to projection effects falsifying the thickness value. The following criteria were used to identify edge-on sheets: (i) crystal structure has to be visible when the sheet extension in beam was small enough $(<50 \mathrm{~nm})$; (ii) lattice planes have to be visible when the sheet extension in beam was smaller than $150 \mathrm{~nm}$ and (iii) image contrast parallel to sheet normal has to be homogeneous for thicker sample (up to micron level). The line-scan in Figure S2 across a nanosheet shows the thickness measurement procedure. The white fringes at the surface of the sheets are an image artifact caused by Fresnel diffraction. All thickness measurements were done from where the contrast turns dark to where the dark contrast ends on the other side of the sheet. This turning point is equivalent to the average electron count surrounding the sheet. Measurement error is related to image resolution which depends on sample thickness and ranges from 0.2 $\mathrm{nm}$ up to about one nanometer. This lower limit of $0.2 \mathrm{~nm}$ measurement error is inconsequential because there are crystallographic limitations to the allowed thickness values. From images of the crystal structure, the sheets are always terminated by (001) or (002) lattice planes. Therefore, the sheet thickness has to be a multiple of $2.52 \mathrm{~nm}$. The upper limit of about one nanometer is valid for crystals which are about $20-40 \mathrm{~nm}$ thick, resulting in a measurement error of only a few percent.

Solid-state ${ }^{31} P$ NMR characterization of acid sites sample preparation. Prior to the adsorption of phosphine oxides onto zeolites, MWW samples were dried at $473 \mathrm{~K}$ for $2 \mathrm{~h}$ in $\mathrm{N}_{2}$ (UHP, Praxair) and transferred into the $\mathrm{N}_{2}$-purged glovebox. A known amount of TMPO or TBPO dissolved in anhydrous $\mathrm{CH}_{2} \mathrm{Cl}_{2}$ was added into a flask containing the dried sample in a glovebox at room temperature. The P-loaded sample was sonicated for $5 \mathrm{~h}$ and then stirred at $500 \mathrm{rpm}$ for over $24 \mathrm{~h}$ at room temperature. Removal of $\mathrm{CH}_{2} \mathrm{Cl}_{2}$ was achieved on a Schlenk line at $313 \mathrm{~K}$. This procedure is a modified version of the preparation approach of Zhao et $\mathrm{al}^{1}$. The sample was then transferred into the $\mathrm{N}_{2}$ glovebox where the sample was transferred into a $\mathrm{ZrO}_{2}$ MAS rotor and then sealed by a gastight Kel-F cap. 
The concentration of total (internal + external) acid sites were quantified by TMPO adsorption, while external active sites were determined by TBPO. The nature of the phosphine oxide was characterized by characteristic ${ }^{31} \mathrm{P}$ shift. The concentration of acid sites was quantified from area ratio from NMR and the total $\mathrm{P}$ content determined by ICP-OES.

Inductively coupled plasma-optical emission spectroscopy (ICP-OES). Inductively coupled plasmaoptical emission spectrometry (Agilent ICP-OES 700) was used to determine the total P content of the zeolite after being titrated by TMPO or TBPO. Typically, $40 \mathrm{mg}$ of the P-loaded MWW sample was dissolved in a mixture of $2 \mathrm{~mL}$ of UA-1 solution (Inorganic Ventures), $0.2 \mathrm{~mL}$ of $70 \%$ nitric acid (BDH) and $10 \mathrm{~mL}$ UNS-1 solution (Inorganic Ventures). After visual confirmation, all of the solid dissolved, DI water was added to adjust the final solution volume to $100 \mathrm{~mL}$. The concentration of $\mathrm{P}, \mathrm{Si}$ and $\mathrm{Al}$ elements were determined using commercial standards (High-purity standards). Three scans were obtained for each element ( $\mathrm{Si}, \mathrm{Al}, \mathrm{P})$ and averaged to determine the concentration of each element from established calibration curves. 


\section{Supporting Tables}

Table S1. Physicochemical Properties of MWW materials

\begin{tabular}{|c|c|c|c|}
\hline Sample $^{\mathrm{a}}$ & $\begin{array}{l}\text { BET surface } \\
\text { area, } \mathrm{m}^{2} / \mathrm{g}\end{array}$ & $\begin{array}{c}\text { External surface } \\
\text { area, } \mathrm{m}^{2} / \mathrm{g}\end{array}$ & $\begin{array}{c}\text { Micropore } \\
\text { volume, } \mathrm{ml} / \mathrm{g}\end{array}$ \\
\hline MCM-22_15 & 634 & 149 & 0.19 \\
\hline $\mathrm{d}-M W W_{4.0-} 15$ & 566 & 183 & 0.16 \\
\hline $\mathrm{d}-M W W_{5.5-} 15$ & 558 & 164 & 0.16 \\
\hline${\mathrm{d}-M W W_{6.0}} 15$ & 585 & 259 & 0.14 \\
\hline $\mathrm{d}-M W W_{7.0} 15$ & 592 & 348 & 0.11 \\
\hline $\mathrm{d}-M W W_{8.0-} 15$ & 557 & 359 & 0.09 \\
\hline $\mathrm{d}-M W W_{9.5-} 15$ & 345 & 350 & 0.00 \\
\hline MCM-22_30 & 626 & 109 & 0.21 \\
\hline $\mathrm{d}-\mathrm{MWW}_{4.0} 30$ & 444 & 133 & 0.13 \\
\hline $\mathrm{d}^{-M W W_{5.0}} 30$ & 392 & 138 & 0.10 \\
\hline $\mathrm{d}^{-M W W_{6.0}} 30$ & 373 & 163 & 0.09 \\
\hline $\mathrm{d}^{-M W W_{7.0}} 30$ & 370 & 228 & 0.06 \\
\hline $\mathrm{d}-\mathrm{MWW}_{8.0} 30$ & 327 & 229 & 0.04 \\
\hline MCM-22_45 & 565 & 76 & 0.19 \\
\hline $\mathrm{d}-\mathrm{MWW}_{4.0-} 45$ & 251 & 144 & 0.06 \\
\hline${\mathrm{d}-M W W_{5.0}} 45$ & 195 & 111 & 0.04 \\
\hline d-MWW $6.0-45$ & 171 & 131 & 0.02 \\
\hline ITQ-2_15 & 662 & 519 & 0.07 \\
\hline ITQ-2_45 & 612 & 506 & 0.06 \\
\hline
\end{tabular}

a. surface area and micropore volume of different MWW-type materials; samples are named MCM-22_X, ITQ-2_X, and d-MWW $\mathrm{y}_{-} \mathrm{X}$ where $\mathrm{X}$ represents the gel Si/Al ratio and y represents the weight percent of CTA. 
Table S2. Elemental composition of as-synthesized MWW materials

\begin{tabular}{lcccc}
\hline Sample $^{\text {a }}$ & Si/Al & Na (wt\%) & Al (wt\%) & Si (wt\%) \\
\hline MCM-22_15 $^{\mathrm{b}}$ & 13.6 & 0.1 & 2.5 & 34.2 \\
d-MWW $_{5.5}{ }^{\mathrm{b}}$ & 13.7 & 0.4 & 2.5 & 34.2 \\
d-MWW $_{8.0}{ }^{\mathrm{b}}$ & 16.7 & 0.4 & 1.8 & 30.0 \\
MCM-22_30 $_{\text {MCM-22_45 }}$ & 26.6 & 0.2 & 1.4 & 37.2 \\
\hline
\end{tabular}

a. elemental composition determined by ICP elemental analysis.

b. mass yield (calcined material) is ca. $1.2 \mathrm{~g}$ for MCM-22 and $0.8 \mathrm{~g}$ for d-MWW $(\mathrm{x}=5.5$ and $8.0 \mathrm{wt} \%)$ 
Table S3. Solid-state ${ }^{31} \mathrm{P}$ NMR peaks $( \pm 2 \mathrm{ppm})$ and fraction of adsorbed TMPO and TBPO on MWW zeolites

\begin{tabular}{|c|c|c|c|c|c|c|c|c|c|c|}
\hline \multirow[b]{2}{*}{ TMPO peak } & \multicolumn{6}{|c|}{ Acid sites } & \multicolumn{4}{|c|}{$\begin{array}{c}\text { Mobile/physisorbed } \\
\text { phosphine oxide }\end{array}$} \\
\hline & 82 & 78 & 69 & 66 & 58 & 53 & 48 & 42 & 36 & 33 \\
\hline $\begin{array}{c}\text { MCM-22 } \\
(\mathrm{Si} / \mathrm{Al}=13.6)\end{array}$ & 0.007 & 0.02 & - & 0.16 & 0.07 & - & - & 0.72 & - & 0.02 \\
\hline $5.5 \mathrm{wt} \%$ & - & - & 0.006 & 0.04 & - & - & 0.23 & 0.48 & - & 0.24 \\
\hline $8.0 \mathrm{wt} \%$ & - & - & - & 0.04 & 0.02 & 0.01 & - & 0.85 & 0.01 & 0.06 \\
\hline $\begin{array}{c}\text { ITQ-2 } \\
(\mathrm{Si} / \mathrm{Al}=20.3)\end{array}$ & - & - & 0.005 & 0.009 & 0.01 & 0.007 & - & 0.96 & - & 0.01 \\
\hline $\begin{array}{c}\text { ITQ-2 } \\
(\mathrm{Si} / \mathrm{Al}=45.0)\end{array}$ & - & - & - & 0.22 & - & - & 0.76 & - & - & 0.02 \\
\hline TBPO peak & 75 & 71 & 62 & - & - & - & 57 & 50 & 46 & - \\
\hline $\begin{array}{c}\mathrm{MCM}-22 \\
(\mathrm{Si} / \mathrm{Al}=13.6)\end{array}$ & 0.037 & - & 0.005 & - & - & - & & - & 0.96 & - \\
\hline $5.5 \mathrm{wt} \%$ & 0.02 & - & 0.008 & - & - & - & & - & 0.97 & - \\
\hline $8.0 \mathrm{wt} \%$ & 0.03 & - & - & - & - & - & & - & 0.97 & - \\
\hline $\begin{array}{c}\text { ITQ-2 } \\
(\mathrm{Si} / \mathrm{Al}=20.3)\end{array}$ & 0.03 & - & - & - & - & - & - & 0.19 & 0.78 & - \\
\hline $\begin{array}{c}\text { ITQ-2 } \\
(\mathrm{Si} / \mathrm{Al}=45.0)\end{array}$ & 0.09 & 0.19 & - & - & - & - & 0.66 & 0.06 & - & - \\
\hline
\end{tabular}


Table S4. Catalytic results for the Friedel-Craft alkylation of benzene and benzyl alcohol ${ }^{\text {a }}$

\begin{tabular}{lccc}
\hline Catalyst & $\begin{array}{c}\text { Conv. } \\
(\%)\end{array}$ & $\begin{array}{c}\text { Yield } \\
\text { DPM (\%) }\end{array}$ & $\begin{array}{c}\text { Yield } \\
\text { DE (\%) }\end{array}$ \\
\hline MCM-22_15 $^{\prime}$ & 63 & 22 & 41 \\
d-MWW $_{5.5}$ & 47 & 11 & 36 \\
d-MWW $_{8.0}$ & 96 & 33 & 63 \\
ITQ-2_15 & $44 \pm 6$ & $12 \pm 2$ & $33 \pm 4$ \\
ITQ-2_45 & 17 & 4 & 13 \\
\hline
\end{tabular}

${ }^{a}$ Reaction conditions: benzene: $8.32 \mathrm{~g}$, benzyl alcohol: $0.54 \mathrm{~g}$, catalyst: $30 \mathrm{mg}, 80^{\circ} \mathrm{C}, 9 \mathrm{~h}$ 


\section{Supporting Figures}

A

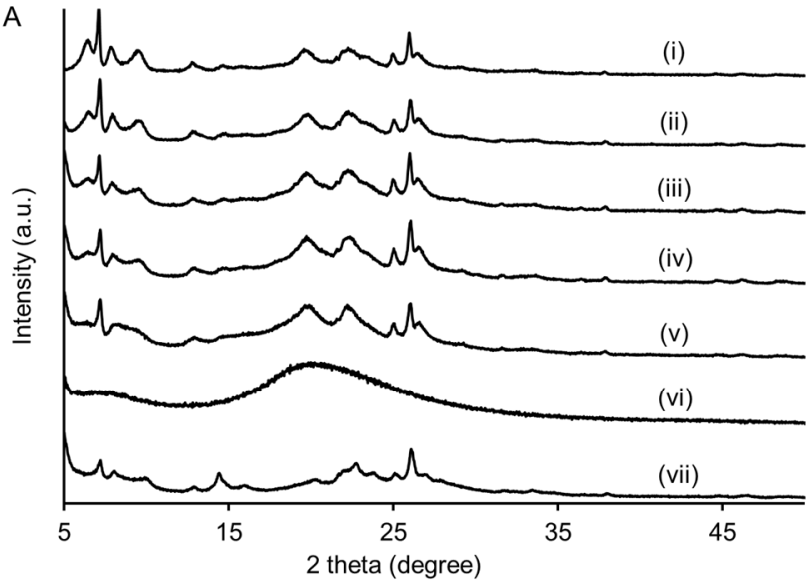

$\mathrm{C}$

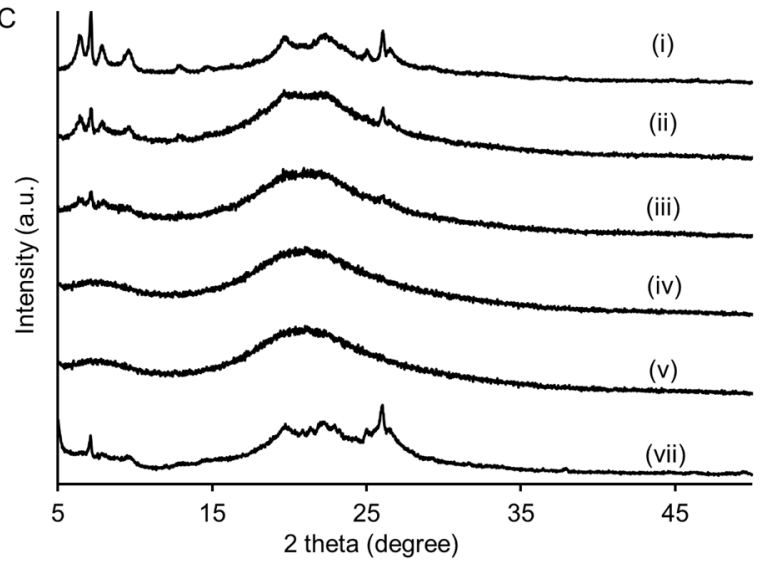

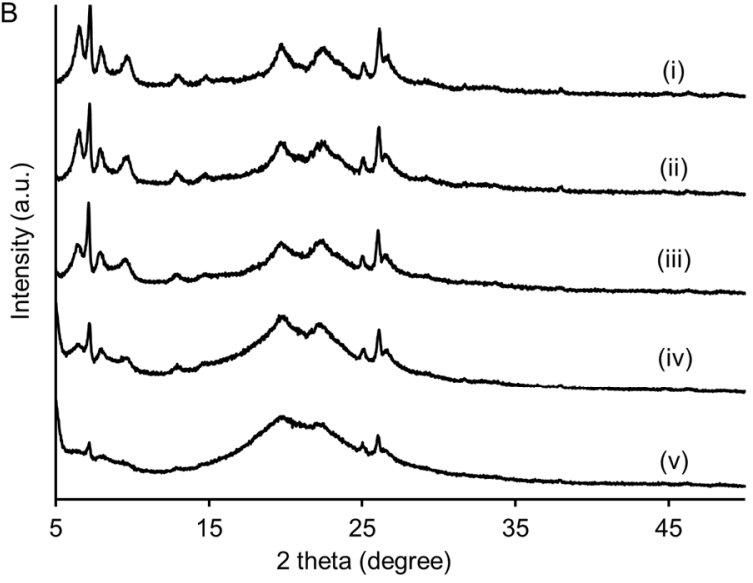

Figure S1. Powder XRD patterns of as-synthesized MWW materials obtained from different starting gel $\mathrm{Si} / \mathrm{Al}$ ratios: (A) 15, (B) 30, and (C) 45. These materials were prepared with (i) 4.0, (ii) 5.0, (iii) 6.0, (iv) 7.0 , (v) 8.0, and (vi) $10.0 \mathrm{wt} \%$ CTA. The synthesis time for all samples was 7 days. Sample (vii) refers to calcined ITQ-2, which was obtained from a synthesis without the addition of CTA using a reported postsynthesis exfoliation procedure. 

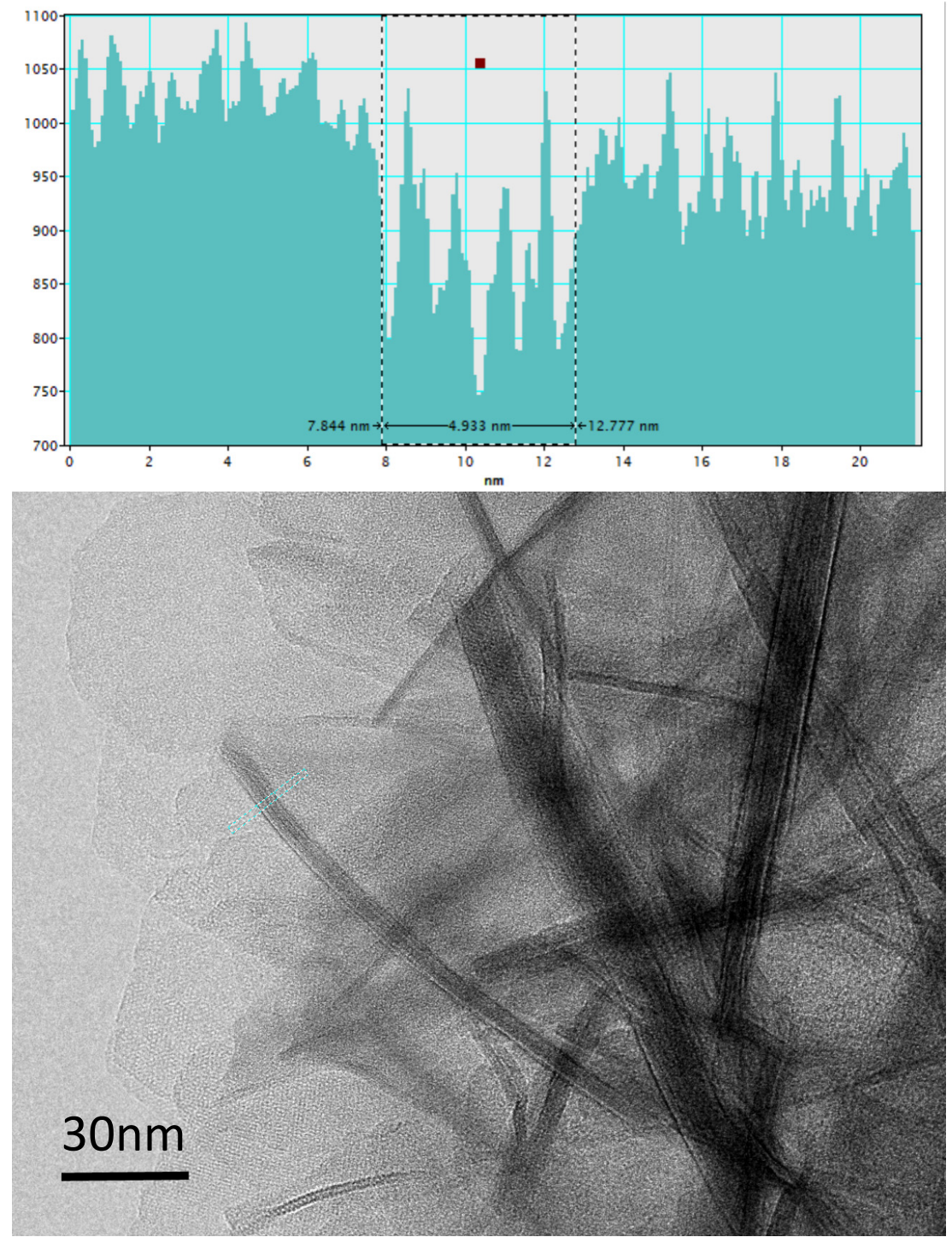

Figure S2. Example of sample thickness measurement for MWW synthesized in the presence of $8.0 \mathrm{wt} \%$ CTA using Digital Micrograph. The line profile clearly shows the edge-on oriented MWW nanosheet is approximately 2 unit cells thick $(\sim 5 \mathrm{~nm})$. 

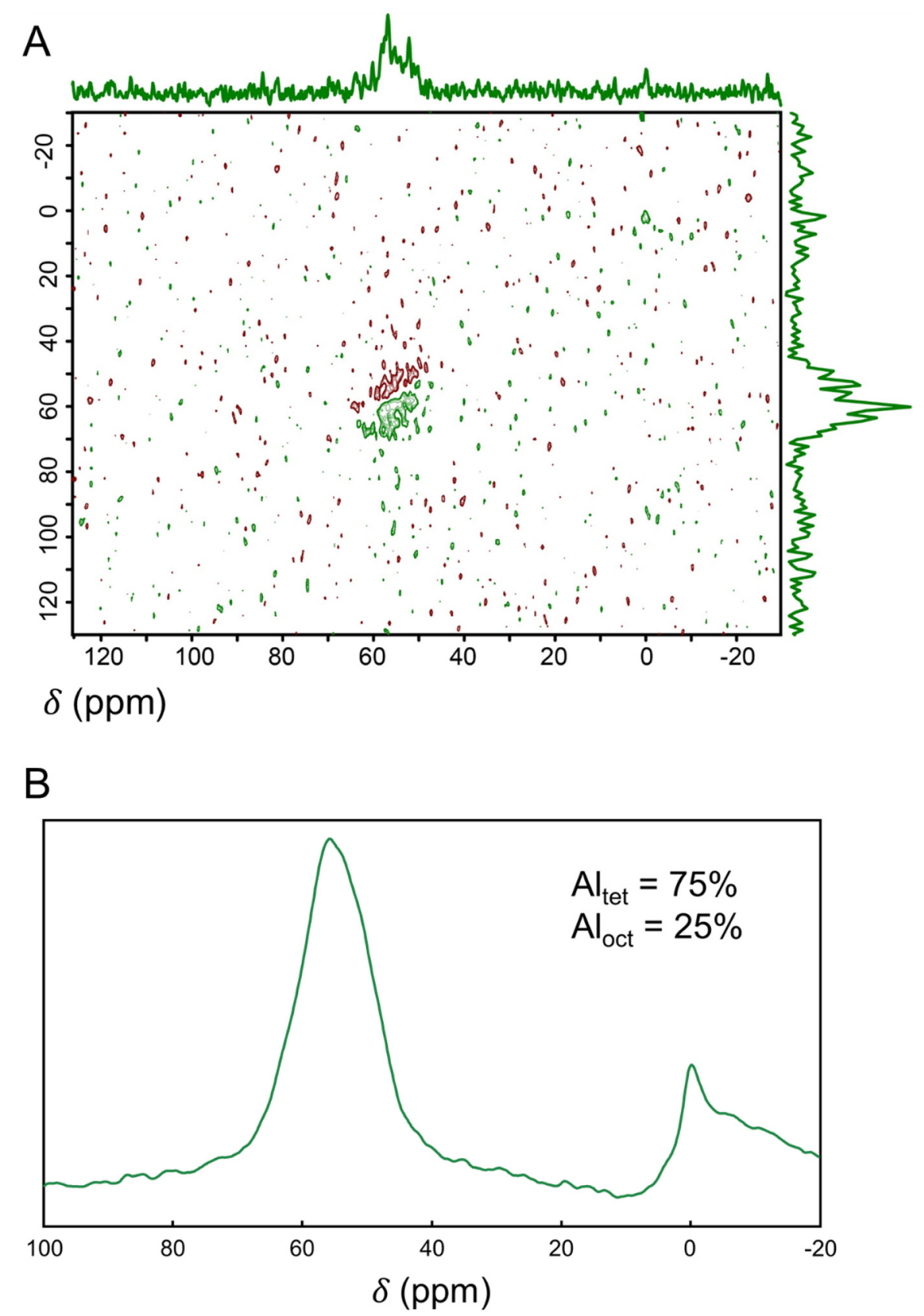

Figure S3. (A). Two-dimensional ${ }^{27} \mathrm{Al}$ MQMAS NMR spectrum of ITQ-2_15 acquired at $11.7 \mathrm{~T}$ and 12.5 kHz. (B). One-dimensional ${ }^{27} \mathrm{Al}$ MAS NMR spectrum of ITQ-2_15 was obtained at a spinning frequency of $12.5 \mathrm{KHz}$ with a $\pi / 12$ pulse width of $1.25 \mu$ s and a recycle delay of $0.8 \mathrm{~s}$. The number of scans was 4096 for all measurements. 

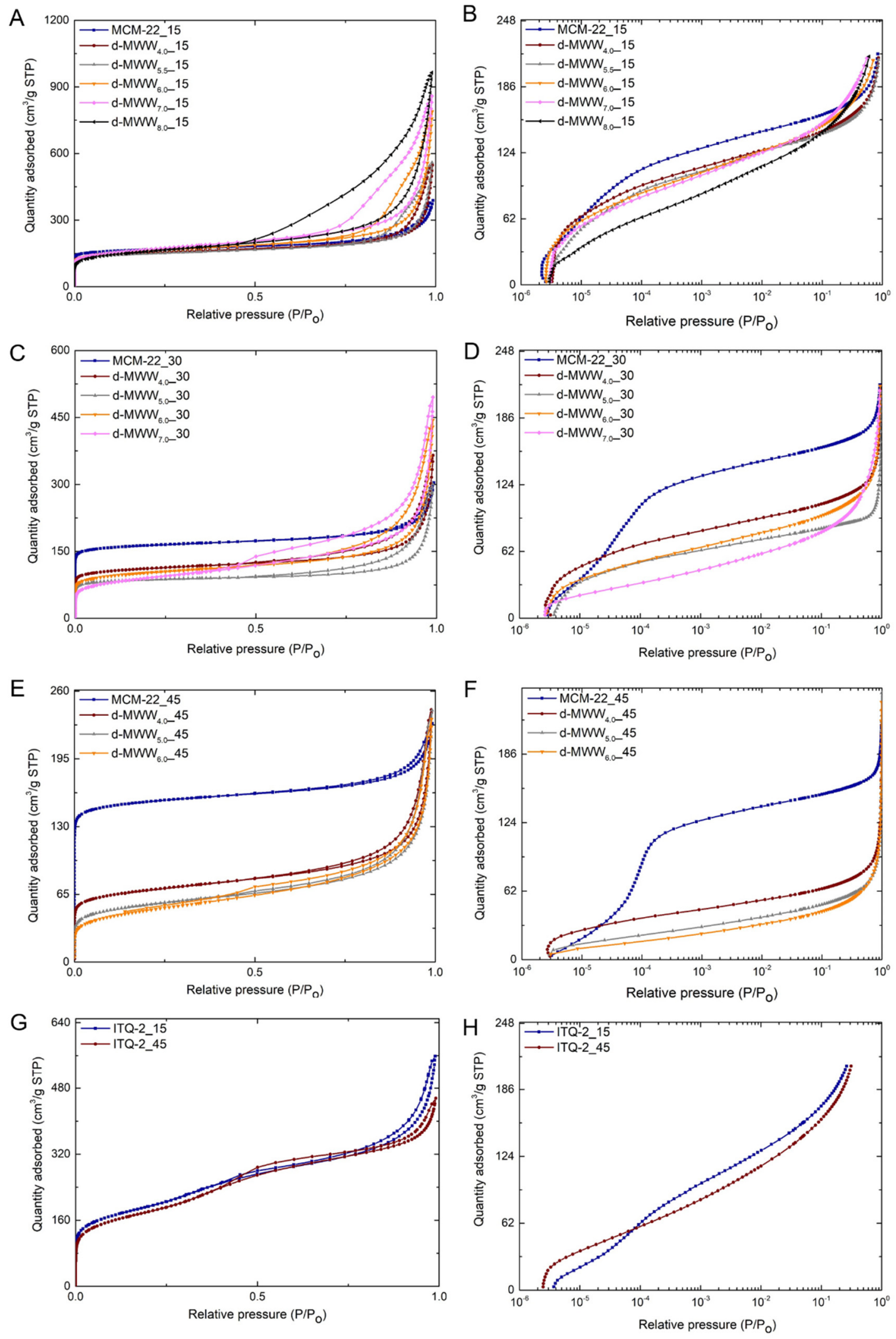

Figure S4. Nitrogen adsorption and desorption isotherms of calcined MWW materials. 

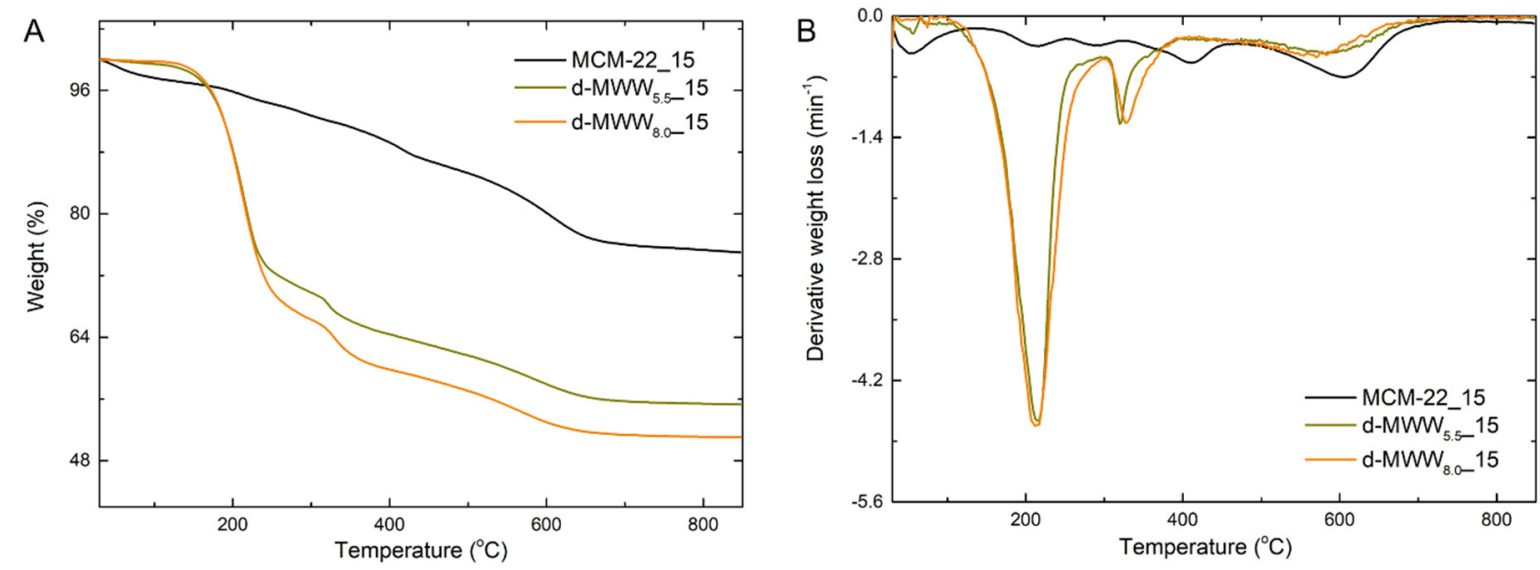

Figure S5. Thermogravimetric analysis (TGA) of as-synthesized MWW materials. 

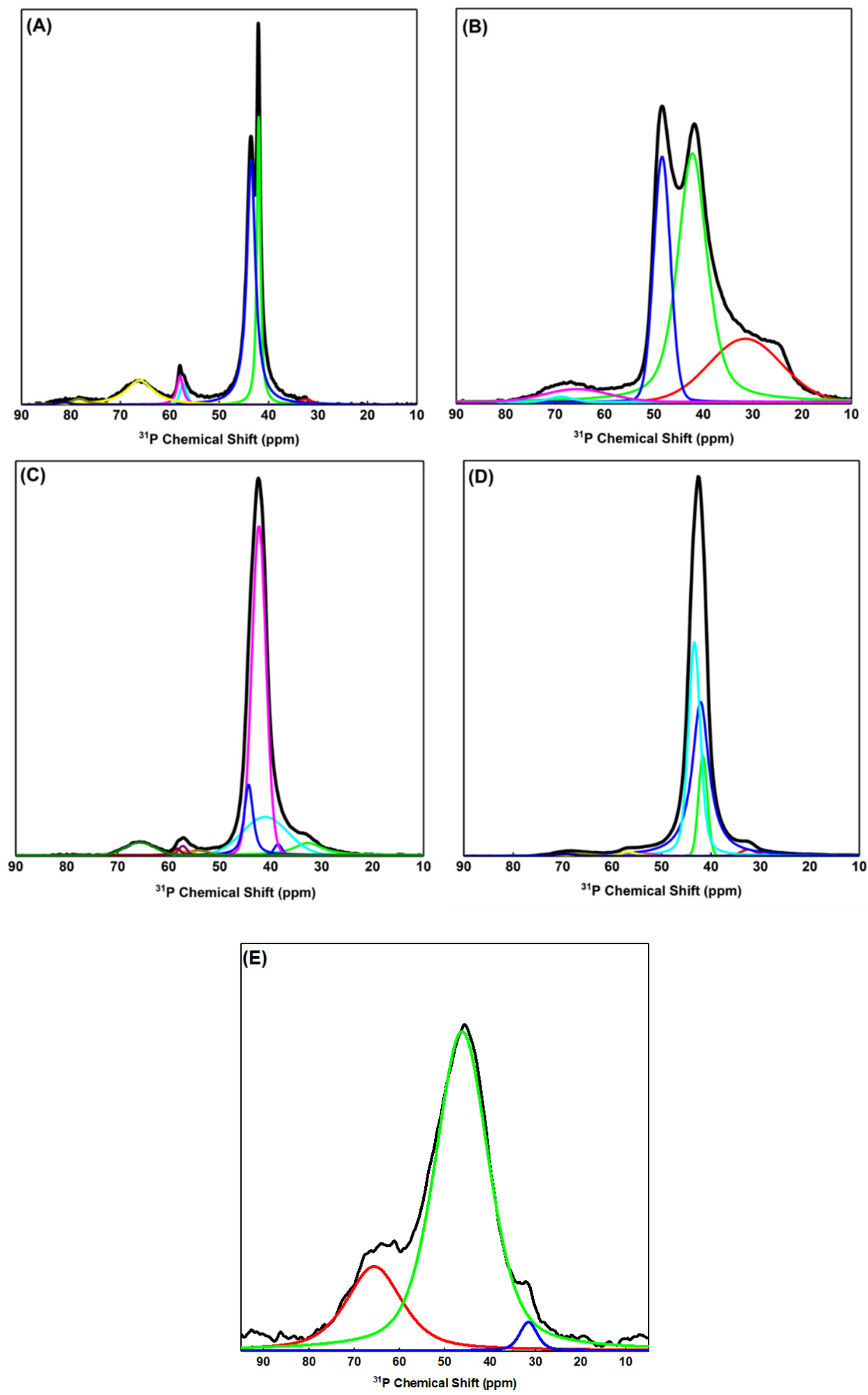

Figure S6. Deconvolution solid-state ${ }^{31} \mathrm{P}$ NMR spectra of TMPO adsorption on MWW-type zeolites: (A) MCM-22_15 (0.0 wt \% CTAB); (B) d-MWW $5.5 \_15$; (C) d-MWW $8.0 \_15$; (D) ITQ-2_15; and (E) ITQ-2_45. 

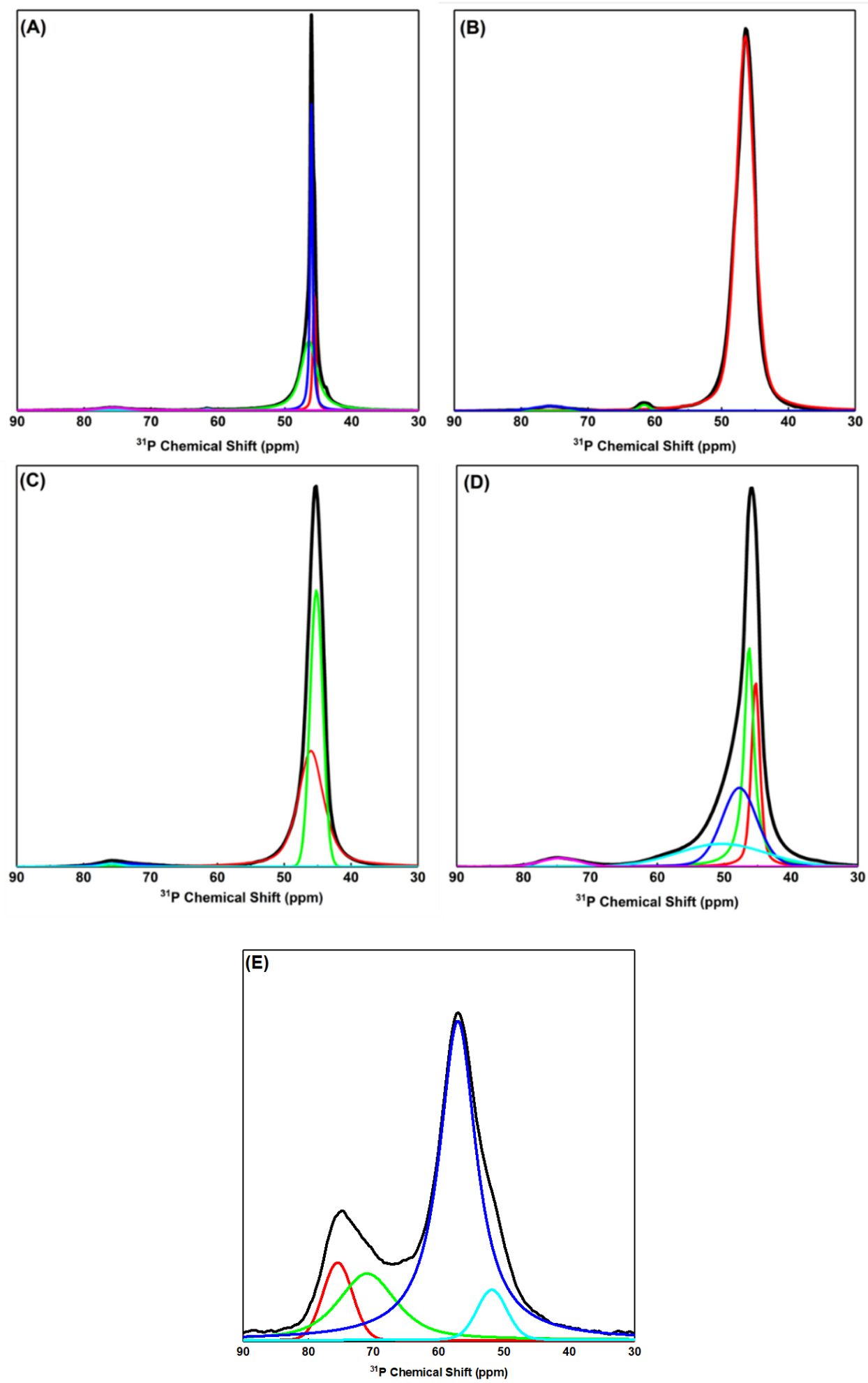

Figure S7. Deconvolution solid-state ${ }^{31} \mathrm{P}$ NMR spectra of TBPO adsorption on MWW-type zeolites: (A) MCM-22_15; (B) d-MWW $5.5 \_15$; (C) d-MWW $8.0 \_15$; (D) ITQ-2_15 and (E) ITQ-2 45. 

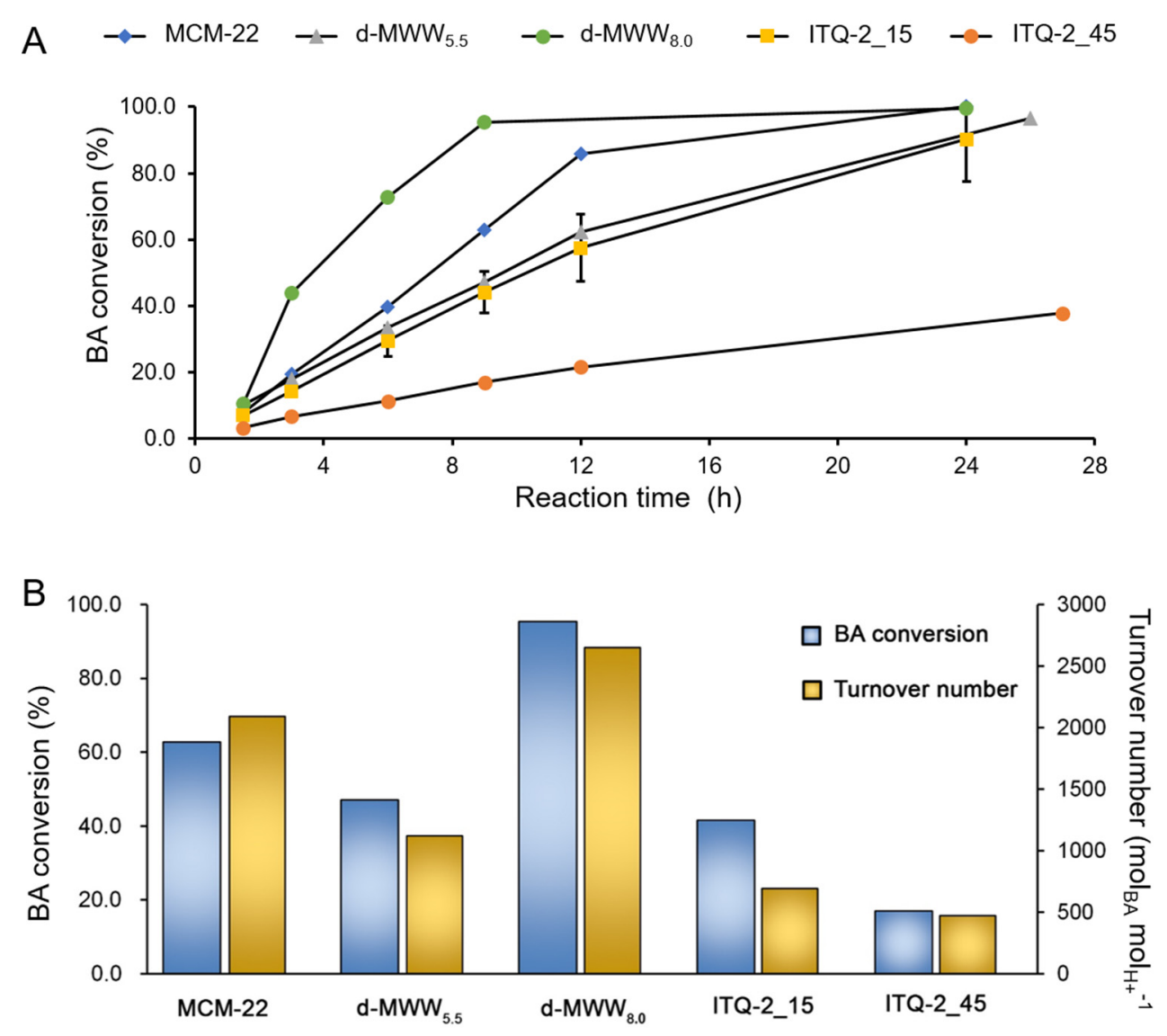

Figure S8. (A) Benzyl alcohol conversion as a function of reaction time over MWW-type (H-form) catalysts. Error bars for ITQ-2_15 are the standard deviation based on three experiments with different batches. (B) Benzyl alcohol (BA) conversion (blue, left axis) at $80{ }^{\circ} \mathrm{C}$ for a fixed catalyst loading (30 $\mathrm{mg}$ catalyst per $8.86 \mathrm{~g}$ reaction mixture; benzene $/ \mathrm{BA}=196 \mathrm{~mol} \mathrm{~mol}^{-1}$ ). The turnover number (yellow, right axis) was calculated as the moles of reacted BA normalized by the moles of external $\left[\mathrm{H}^{+}\right]$acid sites. Data are listed for the following H-form MWW-type samples: H-MCM-22_15, H-d-MWWx (x = 5.5 and 8.0 wt $\%$ CTA, gel Si/Al = 15), and H-ITQ-2 (gel Si/Al = 15 and 45). The results are shown for a single time point $(9 \mathrm{~h})$. 

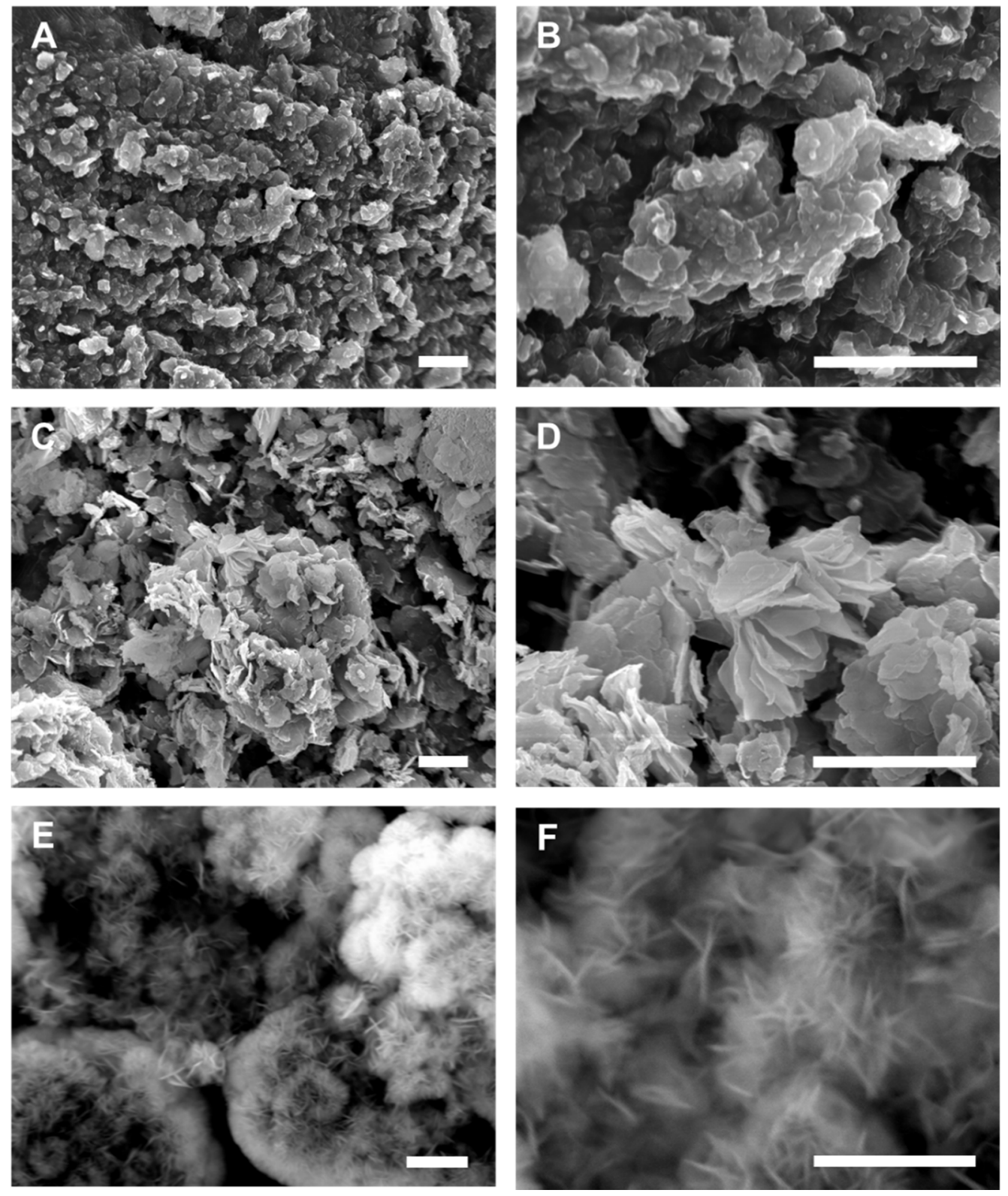

Figure S9. Scanning electron micrographs of calcined MWW type materials: (A and B) H-ITQ-2 (gel Si/Al = 15); $(\mathrm{C}$ and D) H-ITQ-2 (gel Si/Al = 45), and H-d-MWW 5.5 (gel Si/Al = 15). All scale bars are equal to $2 \mu \mathrm{m}$.

\section{References}

(1) Zhao, Q.; Chen, W.-H.; Huang, S.-J.; Wu, Y.-C.; Lee, H.-K.; Liu, S.-B. The Journal of Physical Chemistry B 2002, 106, 4462. 